\title{
Inibição do crescimento de Escherichia coli isolada de Queijo “Minas Frescal” por Lactobacillus acidophilus
}

\author{
Inhibition of the growth of Escherichia coli isolated from 'Minas Frescal' cheese by \\ Lactobacillus acidophilus
}

\author{
Tammy Priscilla Chioda ${ }^{\text {* }}$ Rubén Pablo Schocken-Iturrino ${ }^{\text {II }}$ Gisela Rojas Garcia ${ }^{\text {I }}$ \\ Caroline Peters Pigatto ${ }^{\mathrm{I}}$ César Augusto Martins Ribeiro ${ }^{\mathrm{I}}$ Adriana Valim Ferreira Ragazzani ${ }^{\mathrm{I}}$
} \begin{abstract}
Escherichia coli faz parte da microbiota anaeróbica
facultativa normal, sendo também considerada um dos maiores RESUMO patógenos entéricos predominantes no cólon dos animais e homem. Neste trabalho, realizaram-se ensaios "in vitro" para avaliar o grau de atividade antagonista de cinco cepas de Lactobacillus acidophilus, com capacidade probiótica sobre Escherichia coli BIA 26 (STEC) isolada de queijo "Minas Frescal". Para tanto, foi utilizado o teste de inibição através do método de dupla camada em triplicata para avaliar zonas de inibição de crescimento. Todas as cepas de Lactobacillus mostraram-se capazes de inibir a $\boldsymbol{E}$. coli, com zonas de inibição variando de 12 a $15 \mathrm{~mm}$ de diâmetro, sendo que a maioria apresentou $14 \mathrm{~mm}$ de diâmetro, consideradas como fortes halos de inibição.
\end{abstract}

Palavras-chave: bactéria ácido-lática, probiótico, atividade antagonista, patógenos.

\section{ABSTRACT}

Escherichia coli is part of the normal facultative anaerobic microflora and one of the major enteric pathogens in the colon of animals and humans. In vitro trials were conducted to evaluate the level of antagonistic activity of five strains of Lactobacillus acidophilus with probiotic effect on Escherichia coli BIA 26 (STEC), which was isolated from 'Minas frescal' cheese. Inhibition assays were carried out using the double layer method in triplicates to evaluate growth inhibition zones. All $\mathbf{L}$. acidophilus strains were capable to inhibit $\boldsymbol{E}$. coli, with inhibition zones ranging from 12 to $15 \mathrm{~mm}$, but mostly around $14 \mathrm{~mm}$ in diameter, and considered strong inhibition halos.

Key words: lactic acid bacteria, probiotic, antagonistic action, pathogens.

\section{-NOTA-}

A produção de queijos representa uma das mais importantes atividades da indústria de laticínios, dentre os quais destaca-se o queijo "Minas Frescal", largamente difundido e de grande popularidade (ISEPON \& OLIVEIRA, 1995). Vários estudos realizados com queijo "Minas Frescal” têm permitido o isolamento de inúmeros patógenos de importância em Saúde Pública, destacando-se diversos sorogrupos de Escherichia coli (REID, 2001). Quando presentes nos alimentos, podem ser responsáveis por "doenças microbianas de origem alimentar" ou "toxinfecções alimentares” (FRANCO \& LANDGRAF, 1996). Embora uma variedade de alimentos tenham sido associados à doença implicada pela Escherichia coli O157:H7, a maioria dos surtos ocorrem com o consumo de alimentos crus ou mal cozidos de origem bovina (DOYLE, 1997). A Escherichia coli O157:H7 produz uma ou mais toxinas shiga, muitas vezes chamadas de verocitotoxinas, sendo a mais comum a $\boldsymbol{E}$. coli diarréica, isolada e identificada na América do Norte e na Europa. A E coli 0157 produtora de toxina shiga (STEC) é implicada como a causa de pelo menos $80 \%$ dos casos de Síndrome Urêmica Hemolítica na América do Norte, e também é comumente reconhecida como a causa de diarréia sanguinolenta em países desenvolvidos (BOPP et al., 1999). Assim, ORNELA et al. (2005) observaram o perfil microbiológico do queijo Minas artesanal produzido na região da Serra da Canastra (MG) e, de quarenta amostras analisadas, 50\% atendiam aos

IPrograma de Pós-graduação em Microbiologia Agropecuária, Universidade Estadual Paulista (UNESP), Campus de Jaboticabal, SP, Brasil. E-mail: tammypc@fcav.unesp.br. *Autor de correspondência.

IIDepartamento de Microbiologia, UNESP, Campus de Jaboticabal, Via de acesso Prof. Paulo Donato Castellane s/n, 14884-900, Jaboticabal, SP, Brasil. 
padrões para coliformes a $35^{\circ} \mathrm{C}$ e $50 \%$ para coliformes a $45^{\circ} \mathrm{C}$. Determinadas bactérias láticas utilizam, preferencialmente, a lactose como fonte de carbono, tendo como produtos de seu metabolismo diversas substâncias antimicrobianas como: ácidos orgânicos, peróxido de hidrogênio, dióxido de carbono, diacetil, acetaldeído e bacteriocinas, que atuam favoravelmente no produto alimentício ao qual foram adicionados, fazendo parte dos microrganismos capazes de exercer efeitos benéficos ao hospedeiro. São denominados microrganismos probióticos, apresentando um amplo espectro de ação contra microrganismos patogênicos e deteriorantes NAIDU \& CLEMENS (2000).

Entre as bactérias ácido-láticas, o Lactobacillus acidophilus é considerado um microrganismo com potencial probiótico, sendo utilizado pela indústria de laticínios na elaboração de vários produtos, os quais podem apresentar inúmeras aplicações na nutrição humana como suplementos alimentares, suspensões orais, comprimidos, iogurtes, leites fermentados, no tratamento e prevenção de doenças como efeito anticarcinogênico, no estímulo do sistema imunológico, sendo também capazes de tolerar a acidez do suco gástrico, quando comparados a outras espécies de Lactobacillus (GUEDES NETO, 2002).

O estudo do efeito de probióticos sobre a inibição de patógenos é de grande relevância, e a utilização de bactérias láticas como bioconservadores mostra-se uma alternativa na conservação de produtos alimentícios (RACCAH et al ., 1979; ABDEL - BAR \& HARRIS, 1984; NETTLES \& BAREFOOT,1993; LEUSCHNER \& BOUGHTFLOWER, 2002).

O presente estudo teve por objetivo avaliar a atividade inibitória in vitro de cinco cepas de Lactobacillus acidophilus sobre Escherichia coli BIA 26(STEC).

Durante o período de julho a setembro de 2005, foi realizado o presente experimento, no qual cepas de Lactobacillus acidophilus denominadas P1, P3, P4, P6 e P12, pertencentes à bacterioteca da FCAVUNESP, foram ativadas em tubos com leite desnatado reconstituído a $10 \%$ (previamente esterilizados a $120^{\circ} \mathrm{C}$ durante 20 minutos) e incubadas em anaerobiose a $37^{\circ} \mathrm{C}$, durante 24 a 48 horas, para confirmar sua pureza, sendo, depois, repicadas em tubos contendo Caldo de Man, Rogosa e Sharpe (MRS-Oxoid) a $37^{\circ} \mathrm{C}$, por 18 horas, em anaerobiose. Como microrganismo-desafio, foram utilizadas cepas de Escherichia coli identificadas por BIA 26 produtora de toxina shiga (STEC), isoladas de queijo "Minas Frescal" cepas essas gentilmente fornecidas pelo Dr. J.M. Marin, da Universidade de São Paulo (USP)-Brasil, as quais estavam mantidas em caldo infusão cérebro-coração- BHI (Oxoid) a $37^{\circ} \mathrm{C}$, por 24 horas.
Para avaliar a ação antagônica das cepas de L.acidophilus, realizou-se o teste de inibição com o método de dupla camada, descrito por MAIA et al. (2001). Utilizouse um inóculo contendo $10^{6} \mathrm{UFC} \mathrm{mL}^{-1}$ (determinado a partir da turbidez pela escala de Mac Farland) de cada amostra de Lactobacillus acidophilus. Estes foram colocados em cinco pontos eqüidistantes na superfície de uma placa de ágar MRS (Oxoid) e incubados por 72 horas, a $37^{\circ} \mathrm{C}$, em jarras de anaerobiose (sistema $\left.\operatorname{Gaspak}^{\circledR}\right)$. Após a incubação, as placas foram inundadas com 10ml de clorofórmio, por 20 minutos, sendo, em seguida, abertas em câmara de fluxo laminar para permitir a evaporação total do clorofórmio, quando então foi adicionada uma outra camada de $3,5 \mathrm{ml}$ de BHI Agar (0,75\% de ágar), previamente inoculado com 0,1ml da cultura de Escherichia coli BIA 26. As placas foram incubadas em estufa a $37^{\circ} \mathrm{C}$, por 24 a 48 horas, em aerobiose e avaliadas quanto à presença ou não de halos de inibição de crescimento. Os testes de inibição foram realizados em triplicata para cada cepa antagonista.

Todas as cepas de Lactobacillus acidophilus, denominadas P1, P3, P4, P6 e P12, apresentaram atividade antagonista em todas as repetições, confirmadas através da produção de zonas de inibição contra o microrganismo indicador Escherichia coli BIA 26. Entretanto, o espectro de inibição para as cepas P1, P3 e P6 foi, em média, de 10 a $15 \mathrm{~mm}$ de diâmetro, medido a partir do centro da borda da zona de inibição, os quais são considerados halos fortes, segundo MORENO (1996). Mesmo pertencendo à mesma linhagem, a cepa de $\boldsymbol{L}$. acidophilus $\mathrm{P} 4$ apresentou o halo de $9 \mathrm{~mm}$ de diâmetro, o que é considerado uma inibição média. A cepa de $\boldsymbol{L}$. acidophilus P12, apesar de ter apresentado pouca atividade antagonista, teve zonas de inibição que permaneceram, em média, com halos de 5 a $9 \mathrm{~mm}$ de diâmetro. A variação da formação de um halo para outro apresentado pelas cepas de Lactobacillus acidophilus é fortemente defendida através da produção em maior ou menor quantidade de substâncias antimicrobianas como peróxido de hidrogênio, ácidos orgânicos e bacteriocinas, cujas caracterizações específicas definem tais ocorrências. O espectro inibitório destes resultados está representado na tabela 1.

Os resultados apresentados são similares aos relatadas por TANTILLO et al. (2002), em que cepas de Lactobacillus sake foram capazes de inibir o crescimento de Listeria innocua, Escherichia coli e Pseudomonas aeruginosa através do método de antagonismo. OGAWA et al. (2001) estudaram o efeito inibitório de Lactobacillus acidophilus YIT 0070 sobre Escherichia coli (STEC) O157: H7 baseando-se no controle de $\mathrm{pH}$, relatando que a inibição do crescimento e atividade bactericida de $\mathbf{L}$. acidophilus sobre STEC 
Tabela 1 - Atividade antimicrobiana “in vitro” realizada por cepas de Lactobacillus acidophilus identificadas por P1, P3, P4, P6 e P12 contra E.coli BIA 26 (STEC) isolada de queijo "Minas frescal”.

\begin{tabular}{lcc}
\hline Cepas antagônicas & Escherichia coli BIA 26 Halos de inibição em mm & 15,0 \\
L. $a$ cidophilus-P1 & $(+++)$ & 15,0 \\
L. acidophilus-P3 & $(+++)$ & 9,0 \\
L. acidophilus-P4 & $(++)$ & 15,0 \\
L. acidophilus-P6 & $(+++)$ & 10,0 \\
L. acidophilus-P12 & $(++)$ & \\
\hline
\end{tabular}

Padrão para medida dos halos segundo MORENO (1996) - negativo; +: fraca inibição (halos de até 4mm de diâmetro); ++: média inibição (halos de 5 a 9mm de diâmetro); +++: forte inibição (halos de 10 a $15 \mathrm{~mm}$ de diâmetro).

ocorreu devido à produção de ácido lático e à redução do $\mathrm{pH}$. O antagonismo promovido pelas bactérias láticas assume um papel importante na tecnologia de alimentos, pois está diretamente relacionado com a capacidade de produzir e tolerar uma concentração elevada de ácido lático, permitindo a inibição de outros microrganismos, favorecendo a competição com eles num ecossistema. Considerando a realidade de fabricação de queijos artesanais, sua importância sócioeconômica e, sobretudo, em relação à saúde pública, crescentes avanços estão sendo feitos utilizando bactérias ácido-láticas. Dessa forma, comprova-se que as cepas de Lactobacillus acidophilus estudadas no presente trabalho são eficientes no controle de Escherichia coli BIA 26 (STEC), podendo ser empregadas como bioconservantes.

A habilidade de produzir compostos antimicrobianos e de promover a atividade antagonista contra patógenos como Escherichia coli contribui para eleger as cepas de Lactobacillus acidophilus (P1, P3, P4 , P6 e P12) como culturas probióticas com alto potencial de aplicação na produção de alimentos.

\section{REFERÊNCIAS}

ABDEL-BAR, N.M.; HARRIS, N.D. Inhibitory effect of Lactobacillus bulgaricus on psycrotrophic bacteria in associative cultures and in refrigerated foods. Journal of Food Protection, v.47, p.61-64, 1984.

BOOP, C.A. et al. Escherichia, Shigella and Salmonella. In: MURRAY, P.R. et al. Manual of clinical microbiology. Washington DC: ASM, 1999. p.459-466.

DOYLE, M.P. Isolation of Escherichia coli O157:H7 from retail fresh meats and poultry. Appl Environ Microbiol. n.53, p.2394-2396, 1997.

FRANCO, B.D.G.M.; LANDGRAF, M. Microbiologia dos alimentos. São Paulo: Atheneu, 1996. p.46-50, 144.

GUEDES-NETO, L.G. Lactobacillus acidophilus e a indústria de laticínios. Revista Leite e Derivados, v.66, p.17-23, 2002.

ISEPON, J.S.; OLIVEIRA, A.J. Variação do índice de proteólise e aceitabilidade do queijo "Minas Frescal”. In: CONGRESSO
NACIONAL DE LATICÍNIOS, 13., 1995, Juiz de Fora. Programa Oficial, Resumos. Juiz de Fora: Instituto de Laticínios Cândido Tostes, 1995. p.287.

LEUSCHNER, G.K.R.; BOUGHTFLOWER, P.M. Laboratory -Scale preparation of soft cheese artificially contaminated with low levels of Escherichia coli O157, Listeria monocytogenes, and Salmonella enterica Serovars Typhimurium, Enteritidis, and dublin. Journal of Food Protection, v.65, n.3, p.508514, 2002.

MAIA, O.B. et al. Evaluation of the components of a commercial probiotic in gnotobiotic mice experimentally challenged with Salmonella enterica subsp. enterica ser. typhimurium. Veterinary Microbiology, v.70, p.183-189, 2001.

MORENO, I. Ocorrência e caracterização de bacteriocinas de Lactococos e sua utilização no processamento de queijo "Minas Frescal". 1996. 150f. Dissertação (Mestre em Tecnologia de Alimentos) - Curso de Pós-graduação em Tecnologia de Alimentos, Universidade de São Paulo.

NAIDU, A.S.; CLEMENS, R.A. Probiotics: natural food antimicrobial systems. Boca Raton: CRC, 2000. p.431-462.

NETTLES, C.G.; BAREFOOT, S.F. Biochemical and genetic characteristics of bacteriocins of food- associeted lactic acid bacteria. Journal of Food Protection, v.56 p.338-356, 1993.

OGAWA, M. et al. Inhibition of in vitro growth of Shiga toxinproducing Escherichia coli $0157:$ H7 by probiotic Lactobacillus strain due to production of lactic acid. International Journal of Food Microbiology, v.68, p.135-140, 2001.

ORNELA, E.A. et al. Perfil microbiológico de amostras de queijo minas artesanal produzidos na Serra da Canastra-MG. In: CONGRESSO BRASILEIRO DE MICROBIOLOGIA, 2005, Santos. Anais... Santos: Pró-Reitoria de Pós-graduação e Pesquisa, 2005. p.15581-15581.

RACCAH, M. et al. Potencial application of microbial antagonism to estend storage stability of a fresch type of food. Journal of Food Science, v.44, p.43-46, 1979.

REID, T.M.S.A. Case study of cheese associated E. coli O157 outbreaks. Food and Nutrition, p.201-212, 2001.

TANTILLO, M.G. et al. Bacteriocin-producing Lactobacillus sakei as starter culture in dry sausages. New Microbiology, v.25, p.45-49, 2002. 